https://doi.org/10.18485/kud_kiaz.2019.ch11

\author{
Севда Иманова \\ АзербайджанскийУниверситет Языков
}

\title{
ЯЗЫКОВАЯ ПОЛИТИКА В ГОДЫ НЕЗАВИСИМОСТИ В АЗЕРБАЙДЖАНЕ
}

\section{SUMMARY}

From the first day of establishment of independent state one of the main tasks for our national leader Heydar Aliev was language policy. Prominent politician even during the Soviet period could give an official status to Azerbaijani language. Today in many Universities of the world are opening the centers of Azerbaijani language and culture for studying it.

Key words: Azerbaijani language and culture, language policy, independent state, national leader.

С первых дней построения независимого государства одной из важных задач общенационального лидера была языковая политика. Под языковой политикой подразумевалось совокупность мер, принимаемых государством для изменения или сохранения существующих функционально-языковых норм, а также поддержка языков - общепризнанно, что язык является одним из важных элементов определяющий национальную идентичность, выполняя консолидирующую функцию. Азербайджан многонациональная страна и этот фактор также является частью языковой политики. Одним из самых важных успехов наших стран, в период построения независимых государств, является языковая политика. Это была очень мудрая, необходимая стратегия. 
Как известно, наш национальный лидер Гейдар Алиев один из таких выдающихся личностей, что подрастающее поколение, даже с течением времени обращается к его богатому наследию, анализируют и изучает его жизненный путь. Гейдар Алиев, еще в годы советской власти был руководителем, который рассматривал вопрос родного языка как средство выражающее сущность народа. Еще в 70-е годы прошлого века, когда народ жил под сильным идеологическим давлением, на внеочередной VII сессии Верховного Совета Азербайджанской СССР IX созыва, была принята новая Конституция, где в 73-ей статье Конституции азербайджанский язык был утверджден как государственный язык. Это стало возможным благодаря Гейдару Алиеву, руководившим Азербайджаном в тот период. Наш национальный лидер, опираясь на свой политический опыт, высокий интеллект, проводил целенаправленную работу, направленную на развитие родного языка и несмотря на трудности того периода сумел предпринять важные шаги. Конечно, для того времени, это считалось настоящим героизмом. В отличии от других союзных республик, в Азербайджане во всех государственных структурах и организациях, научных и учебных заведениях наряду с русским языком, азербайджанский язык также стал ведущим языком.

В первые годы восстановления независимости Азербайджан был в парализованном состоянии: с одной стороны война с сепаратистами, 20\% оккупированных территорий, более миллиона беженцев и вынужденных переселенцев, а с другой стороны внутренние противоречия, политический кризис, борьба за власть, в результате которой создалась реальная угроза гражданской войны. В эти тяжелые времена, по зову народа, Гейдар Алиев вернулся в политическую жизнь страны и был избран президентом. Возглавив Азербайджан Гейдар Алиев в кратчайшие сроки добился больших успехов во всех сферах внутренней и внешней политики. 
C первых дней построения независимого государства общенациональный лидер уделял большое внимание азербайджанскому языку. Он был твердо убежден в том, что только: «Родным языком создается каждый народ».

В 1995 году была принята Конституция Азербайджанской Республики. В этом документе был определен статус языка как единственного государственного. Но также было гарантировано свободное использование других языков населения страны. Например, граждане Азербайджана имеют право свободного выбора языка для получения образования.

Для тех, кто хочет получить образование на грузинском языке, в Гахском, в Шекинском, Закатальском, Белаканском районах функционируют 10 школ. По данным минестерства образования, в нашей стране действуют 222 школы на талышском языке, 19 на аварском , 102 на лезгинском, 5 на цахурском , 1 на курдском языках. Все это стало возможным благодаря мудрой языковой политике нашего национального лидера.

Азербайджанский язык является средством общения и официальным государственным языком Азербайджанской Республики который прошел долгий путь развития. Возраст нашего устного, литературного языка, если считать со времен эпосов «Китаби Деде Горгуд», может считаться более 1300 лет.

Сегодня во многих университетах мира открываются центры азербайджанского языка и культуры, где изучают азербайджанский язык. Такие центры функционируют в России, Индонезии, Сербии и Китае. Эти достижения в сфере внешней языковой политики, являются прямым результатом дальновидной политики, основы которой были заложены общенациональным лидером азербайджанского народа Гейдаром Алиевым.

Азербайджан является ярким примером мультикультуральной страны, которая осуществляет языковую политику, предупреждающую возможные конфликты на 
этнической почве, учитывая тот факт, что в республике живут много национальностей. Благодаря этой политике Азербайджан сегодня является надежным, стабильным, мультикультуральным, международным партнёром для многих стран.

\section{Литература:}

Yusifov Mübariz. Dövlətçilik və dil. Bak1, "Nurlan”, 2009. səh. 9. http://www.azerbaijan.az/Portal/General/Constitution01.a.html AZORBAYCAN RESPUBLIKKASININ KONSTITUSIYYASI https://edu.gov.az/ru

\section{PЕЗЮMЕ}

С первых дней построения независимого государства, одной из важных задач общенационального лидера была языковая политика. Дальновидный политик еще в годы советского правления добился предоставления азербайджанскому языку статуса государственного языка. Сегодня во многих университетах мира открываются центры азербайджанского языка и культуры где изучают азербайджанский язык.

Ключевые слова; центры азербайджанского языка и культуры, языковая политика, независимая государства, общенациональный лидер. 